\title{
Investigation on the surface properties of chemically modified natural fibers using inverse gas chromatography
}

\author{
Nereida Cordeiro ${ }^{a}$, Mariana Ornelas $^{\mathrm{a}}$, Alireza Ashori ${ }^{\mathrm{b}, *}$, Shabnam Sheshmani $^{\mathrm{c}}$, Hor Norouzi $^{\mathrm{c}}$ \\ a Competence Center in Exact Science and Engineering, University of Madeira, Funchal, Portugal \\ ${ }^{\mathrm{b}}$ Department of Chemical Technologies, Iranian Research Organization for Science and Technology (IROST), Tehran, Iran \\ c Department of Chemistry, Shahr-e-Rey Branch, Islamic Azad University, Tehran, Iran
}

\section{A R T I C L E I N F O}

\section{Article history:}

Received 21 September 2011

Received in revised form 21 October 2011

Accepted 2 November 2011

Available online 9 November 2011

\section{Keywords:}

Alkaline treatment

Fibers modification

Inverse gas chromatography

Surface properties

\begin{abstract}
A B S T R A C T
This paper presents the application of inverse gas chromatography (IGC) technique for characterization and comparison of the surface properties of the natural fibers as reinforcement fillers in wood plastic composites. The effects of chemical modification using $1 \% \mathrm{NaOH}$ were also studied. The fibers used for this work were Iranian cultivated eucalyptus, spruce, bagasse, and wheat straw. Chemical composition of fibers was found to be modified after treatment as characterized by Fourier transform infrared spectroscopy (FTIR). The crystallinity of fibers and the specific interaction was improved by the alkaline treatment, with more relevance to the agro-fibers. The IGC shows also a general increase in the wettability of the modified fiber when compared with the raw (unmodified) samples. Alkaline treatment achieves the best overall improvement in the properties evaluated of the agro-fibers when compared to the wood fibers.
\end{abstract}

(C) 2011 Elsevier Ltd. All rights reserved.

\section{Introduction}

Composite materials based on natural fibers, namely wood plastic composites (WPCs), demonstrate remarkable environmental and economical advantages (Ziaei Tabari, Nourbakhsh, \& Ashori 2011). Although the use of wood flour in plastic composites has several advantages over inorganic fillers, several drawbacks (limitations) of natural fibers such as low compatibility and low thermal stability, greatly reduce the overall performance of WPCs (Hamzeh, Ashori, \& Mirzaei, 2011).

Wood, the most durable organic material, is a three dimensional polymeric composite, made up mainly of cellulose, hemicellulose and lignin. All species of wood and other plant tissues contain small to moderate quantities of chemical substances in addition to the macromolecules, namely extractives. Extractives content in most temperate and tropical wood species are $4-10 \%$ and $20 \%$ of the dry weight, respectively (Sjöström, 1993). Although extractives contribute merely a few percent to the entire wood composition, they have significant influence on its properties (Sheshmani, Ashori, \& Farhani, 2012).

It is well known that the performance, for example the mechanical properties, of WPCs depend on the properties of the individual components and their interfacial compatibility. The interface between hydrophobic plastic and hydrophilic wood is typically

\footnotetext{
* Corresponding author. Tel.: +98 228 2276637; fax: +98 2282276265.

E-mail address: ashori@irost.org (A. Ashori).
}

weak and fails to transfer stress. The effective use of wood particles in WPCs requires a fundamental understanding of the structural and chemical characteristics of wood. For example, a few reports have been published about the effects of wood extractives on the strength properties of the resulting WPCs (Kim, Harper, \& Taylor, 2009; Shebani, van Reenena, \& Meincken, 2009; Sheshmani et al., 2012). Wood extractives are hydrophobic substances with low molecular weights. In the preparation of WPCs, wood flour is thoroughly mixed with a thermoplastic at high temperatures, e.g. $170^{\circ} \mathrm{C}$. At such high temperature, wood extractives may tend to migrate to the wood flour surface, thus accumulating in the woodplastic interphase (Nourbakhsh, Ashori, Ziaei Tabari, \& Rezaei, 2010).

In recent years, inverse gas chromatography (IGC) has been used to characterize and optimize the interaction of natural fibers and polymer composites (Cordeiro, Gouveia, \& Jacob John, 2011; Cordeiro, Gouveia, Moraes, \& Amico, 2011; Tze, Wålinder, \& Gardner, 2006). The technique uses a solid phase packed into a column, and the column is placed in an oven. The temperature is controlled, as a gas mobile phase flows through the column where an inert carrier gas contains "infinitely dilute" samples of probe gases. A detector measures the time required for the probe gases to go through the packed column. The retention time is then related to thermodynamic quantities to characterize the solid phase sample. The fiber/matrix acid base interaction can be quantified using IGC by matching the acidic parameter $\left(K_{\mathrm{a}}\right)$ of one component with the basic component $\left(K_{\mathrm{b}}\right)$ of the other component, and then, measuring the enthalpy of adsorption of the resin onto the fibers 
Table 1

Chemical compositions of used raw fibers (w/w, \% of dry material).

\begin{tabular}{lllll}
\hline Components & Eucalyptus & \multicolumn{1}{l}{ Spruce } & Bagasse & Wheat straw \\
\hline Holocellulose & $74.0 \pm 1.9$ & $72.0 \pm 2.3$ & $73.7 \pm 4.3$ & $63.3 \pm 4.1$ \\
Hemicellulose $^{\mathrm{a}}$ & $18.5 \pm 0.9$ & $27.0 \pm 1.2$ & $33.2 \pm 1.8$ & $25.8 \pm 2.2$ \\
Alpha-cellulose & $55.5 \pm 2.2$ & $45.0 \pm 1.7$ & $40.5 \pm 3.2$ & $37.5 \pm 1.0$ \\
Lignin & $26.4 \pm 2.0$ & $19.0 \pm 0.8$ & $20.7 \pm 1.5$ & $28.6 \pm 1.8$ \\
NaOH solubles & $14.7 \pm 0.8$ & $8.6 \pm 0.6$ & $31.8 \pm 4.3$ & $12.2 \pm 1.1$ \\
\hline
\end{tabular}

a Determined by the difference between holocellulose and $\alpha$-cellulose contents.

(Belgacem and Gandini, 1999). This will allow for the prediction of the acid-base interactions of the natural fibers with the polyester matrix. Based on this, the selection of an appropriate coupling agent for the natural fibers may be made.

In the present study, IGC was used to characterize exhaustively the surface properties of several natural fibers (spruce, eucalyptus, bagasse, and wheat straw). The surface characteristics were evaluated and co-related to the changes occurring during the chemical modification.

\section{Experimental procedures}

\subsection{Materials}

The lignocellulosic materials used in this study were eucalyptus, a hardwood sample, spruce, a softwood sample, and two agrowaste samples: bagasse and wheat straw. All samples were taken from the southern and northern parts of Iran. The samples were separately ground into a fine "meal" using a Wiley mill. The ground meals were screened and the particles that passed through BS 40 mesh $(425 \mu \mathrm{m})$ and retained at BS 60 mesh $(250 \mu \mathrm{m})$ sieve screens were used for chemical treatment. The samples were dried and stored in sealed plastic bags prior to testing.

The chemicals used, namely $\mathrm{NaOH}$, acetic acid and sodium hypochlorite, were all of analytical grade.

IGC measurements were carried out on the samples using several non-polar and polar molecules, all GC grade ( $>99 \%$ purity) supplied by Sigma-Aldrich. The methane, used as a non-interacting reference probe, and the carrier gas, helium, had the high purity (>99.99\%) and were supplied by Air Liquide Company.

\subsection{Chemical characterization}

The chemical characterization of the above-mentioned samples was carried out following the appropriate TAPPI Test Methods (2002) and the other published procedures as indicated. The samples were subjected to the following determinations: holocellulose (Wise \& Karl, 1962), $\alpha$-cellulose (T $203 \mathrm{~cm}$-99), Klason lignin (T 222 om-02), (T 212 om-98). Table 1 shows the mean and standard deviations of three replicate determinations of each sample.

\subsection{Chemical modifications}

The chemical treatment was done following the standard outlined in the TAPPI Test Methods (T 212 om-98). A weighed sample of ground fiber $(2 \mathrm{~g}$ ) was placed in $200 \mathrm{~mL}$ beaker, then $1 \% \mathrm{NaOH}$ solution $(100 \mathrm{~mL})$ was added and the mixture stirred with a glass rod. The beaker was placed in a water bath maintained at $97-100^{\circ} \mathrm{C}$ for a period of $60 \mathrm{~min}$. At the end of this time, the fibers were transferred to a tared filtering crucible and washed with hot water. A solution of $10 \%$ aqueous acetic acid $(25 \mathrm{~mL})$ was then added and the extracted fiber allowed to soak for $1 \mathrm{~min}$ before filtering. After repeating this stage, the material was finally washed with hot water until acid free. The crucible and contents were oven-dried (for $24 \mathrm{~h}$ at $105 \pm 3^{\circ} \mathrm{C}$ ), and $1 \% \mathrm{NaOH}$ extractive percent was determined gravimetrically. These results are so-called "NaOH solubles" and listed in Table 1.

\subsection{Inverse gas chromatography}

IGC measurements were carried out on a commercial inverse gas chromatograph (Surface Measurements Systems, London, UK), that is equipped with a flame ionization detector (FID) and a thermal conductivity detector (TCD). The IGC system is fully automatic with SMS IGC Controller V 1.8 Control Software. Data was analyzed using IGC Standard Analysis Suite V 1.3 and IGC Advanced Analysis Suite $\mathrm{V}$ 1.21. The calculation methodology is described and detailed in Cordeiro, Gouveia, and Jacob John (2011). The columns used were standard glass silanized (dymethyldichlorosilane; Repelcote BDH, $\mathrm{UK}$ ), with $6 \mathrm{~mm} \mathrm{OD}, 300 \mathrm{~mm}$ length and an internal diameter of $4 \mathrm{~mm}$.

The columns were packed with about $1 \mathrm{~g}$ of the samples (raw and modified) with granulometry lower than 40 mesh. The samples were packed by vertical tapping for $2 \mathrm{~h}$, using the SMS sample packing device. The columns with raw and modified natural fibers were conditioned over-night at $333 \mathrm{~K}$ and $10 \mathrm{~mL} / \mathrm{min}$ of helium flow rate, and then conditioned for $2 \mathrm{~h}$ at the temperature of analyses and $0 \%$ relatively humidity. After conditioning the columns, pulse injections were carried out with $0.25 \mathrm{~mL}$ gas loop. Methane was the tracer molecule used to calculate the dead time.

Five $n$-alkanes (hexane, heptane, octane, nonane and decane) were used to measure the dispersive component of the surface energy at four different temperatures; 293, 296, 298, and $300 \mathrm{~K}$. Four polar probes; tetrahydrofuran (THF), ethyl acetate, ethanol, and acetonitrile were used at the same conditions, to study Gibbs specific free energy and acid-base surface character. The permeability and the isotherm experiments were done using the $n$-octane as the probe molecule at $298 \mathrm{~K}$. All the experiments were performed at $0 \% \mathrm{RH}$. The experiments were done in duplicate and the presented results are the average values. The experimental error due to the temperature variation, flow rate and retention time measurement was estimated to be below $3 \%$.

\subsection{Infrared spectroscopy}

Fourier transform infrared spectroscopy (FTIR), Tensor ${ }^{\mathrm{TM}} 27$, Bruker Optics, Billerica, was used to identify the raw and modified fibers by measuring the transmitted radiation of various infrared light wavelengths. Powdered samples were mixed with $\mathrm{KBr}$ (sample/ $\mathrm{KBr}$ ratio, 6/94) to prepare pastilles. FTIR spectra were recorded in a spectral range of $4000-400 \mathrm{~cm}^{-1}$ with a resolution of $4 \mathrm{~cm}^{-1}$ and with 32 scans.

\subsection{X-ray diffraction}

The crystallinity of raw and modified natural fibers (in powder shape) was evaluated by X-ray diffraction (XRD). X-ray patterns were obtained with a PHILIPS X-ray diffractometer model PW 1800 under the following conditions: $\mathrm{CuK}_{\alpha}$ radiation, $30 \mathrm{kV}$ and $17.5 \mathrm{~mA}$. A step size of $0.02^{\circ}$ and a step scan of $2.5 \mathrm{~s}$ were used for the entire reading range $\left(4-60^{\circ}\right)$.

The degree of crystallinity was expressed by the crystallinity index (CI), using Eq. (1), where $I_{002}$ is the maximum peak intensity at a $2 \theta$ angle around $22^{\circ}$, representing crystalline part, and $I_{101}$ is the maximum peak intensity at $2 \theta$ angle around $18^{\circ}$, representing amorphous part. This method developed by Segal, Creely, Martin, and Conrad (1959) has been widely applied to study natural fibers.

$\mathrm{CI}=\left(1-\frac{I_{101}}{I_{002}}\right) \times 100$ 


\section{Results and discussion}

In their natural state, and before chemical extraction, the fibers surface is covered with a layer of substances such as oils, waxes and other encrusting substances, as hemicelluloses, lignin and pectin that form a tick outer layer to protect the cellulose inside. In general, during chemical treatment of the fibers, most of the surface waxes and other non-cellulosic substances are removed. When agro-based fibers are used as reinforcing fibers for composites, the removal of surface waxes and encrusting substances makes the fiber surface rough and improves the adhesion of fibers and polymer matrix (Eichhorn, Bailie, Zafeiropoulos, \& Mwaikambo, 2001).

Chemical, biological and physical treatments are used to improve the morphological features, processability and utility of the fibers (Eichhorn et al., 2001; Gañán, Cruz, Garbizu, Arbelaiz, \& Mondragon, 2004; Nourbakhsh et al., 2010; Reddy \& Yang, 2005). In recent years, some research work has been conducted on surface characteristics of natural fiber modified by different methods, the alkaline treatment being one of the most used (Cordeiro, Gouveia, \& Jacob John, 2011; Mills, Gardner, \& Wimmer, 2008). The physicochemical properties of natural fibers usually changed significantly, depending on the concentration of the chemical agent and duration of processing time.

In the present study, a chemical treatment was used - the alkaline treatment or mercerization - to improve the adhesion between the fibers and matrix. The effect of alkali on cellulosic fibers is a swelling reaction, during which the native cellulose can be changed into different polymorphous forms. The type of alkali $(\mathrm{KOH}, \mathrm{LiOH}$, $\mathrm{NaOH}$ ) and its concentration will influence the degree of swelling, and hence, the degree of lattice transformation of the cellulose (Fengel \& Wegener, 1983). The alkali solution influences not only the cellulosic components inside the plant fiber but also the noncellulosic components (hemicelluloses, lignin, and pectin) (Van de Weyenberg, Chi Truong, Vangrimde, \& Verpoest, 2006).

\subsection{Chemical characterization}

As the main components of the lignocellulosic fibers are cellulose, lignin and hemicelluloses, the obtained FTIR spectral bands was attributed mainly to these components. Fig. 1(a) shows as example the FTIR spectra of the raw spruce and wheat straw fibers. Identification reveals lines representing the hydrogen bondend stretching bands of $\mathrm{OH}$ groups in the region of $3400 \mathrm{~cm}^{-1}$ and in the region of $1030-1150 \mathrm{~cm}^{-1}$, the absorptions can be attributed mainly to the carbohydrates, including $\mathrm{C}-\mathrm{O}-\mathrm{C}$ and $\mathrm{C}-\mathrm{O}$ stretch (primary and secondary hydroxide groups) and bonds belonging to the glucoside linkage and possibly to lignin, since lignin has hydroxyphenyl, guaiacyl and syringyl groups, which are aromatic $\mathrm{OH}$ compounds. The peaks in the region of $2900 \mathrm{~cm}^{-1}$ are due to the aliphatic saturated C-H stretching vibration in lignin/polysaccharides complex. The peaks in the region at $1740 \mathrm{~cm}^{-1}$ in the raw (unmodified) fibers are attributed to either the acetyl and uronic ester groups of the hemicelluloses or the ester linkage of carboxylic group of the ferulic and $p$-coumeric acids of lignin and/or hemicelluloses (Alemdar \& Sain, 2008; Cherian et al., 2008). The bands in the region $1250-1056 \mathrm{~cm}^{-1}$ involve the $\mathrm{C}-\mathrm{O}$ stretching vibrations of aliphatic primary and secondary alcohols in cellulose, hemicelluloses, lignin and extractives (El-Zawawy, 2006). The peak at $897 \mathrm{~cm}^{-1}$ is due to $\beta$-glycosidic linkages of glucose ring of cellulose (Gañán et al., 2004).

The quantification of the main components of the fibers under study was made by standard methods and the results were resumed in Table 1 . These analyses show that the wheat straw fibers have the higher content in lignin (28.6\%) and a lesser content in cellulose

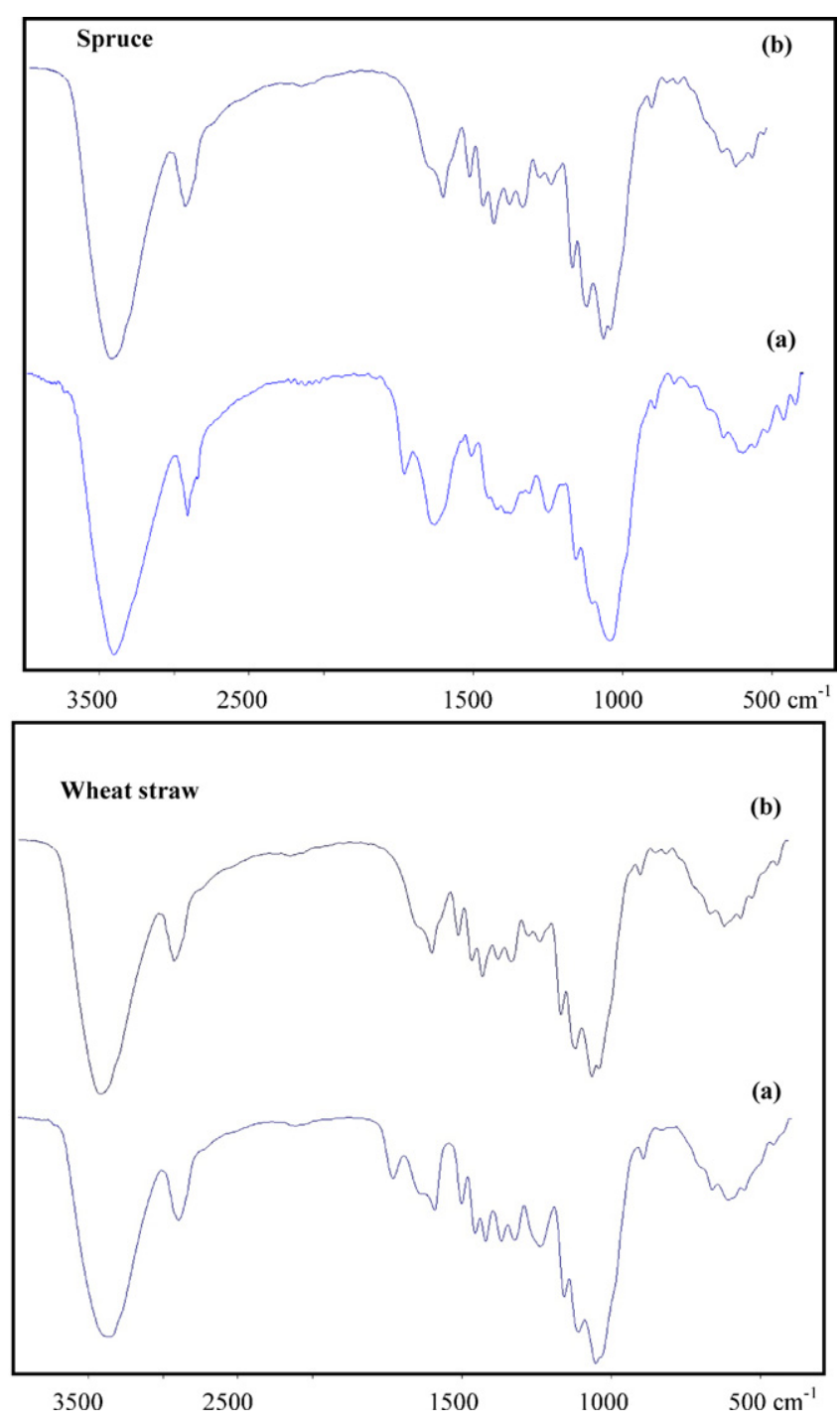

Fig. 1. FTIR spectra of spruce and wheat straw, before (a) and after (b) NaOH treatment.

(37.5\%). On the other hand, spruce presents the smaller content in lignin (19.0\%) and the Eucalyptus has the higher content in cellulose (55.5\%).

Native cellulose (i.e. cellulose as it occurs in nature), the main component of all the samples under study, can be found in the crystalline or amorphous form and can be observed by X-ray diffractograms. X-ray patterns were obtained for all the samples and are shown in Fig. 2 for the eucalyptus and wheat straw fibers. The occurrence of two more intense peaks, close to the values of $2 \theta=16^{\circ}$ and $2 \theta=22^{\circ}$, representing the cellulose crystallographic planes $I_{101}$ and $I_{002}$, respectively, can be observed. These peaks can be attributed to crystalline scattering and the diffuse background associated with disordered regions. The samples show similar X-ray diagrams to wood fibers with a more intense peak at $2 \theta=22^{\circ}$, which is indicative of a more amount of crystalline cellulose in the raw wood fibers. The crystallinity index (CI), calculated according to Eq. (1) and presented in Table 2, collaborated with this observation: raw wood fibers have the higher $\mathrm{CI}(54 \%)$ and agro-fibers the less $\mathrm{CI}(45-49 \%)$. This smaller $\mathrm{CI}$ in the agrofibers is due to the higher presence of non-crystalline extractive free components.

To improve the adhesion between the fibers and matrix, the four different fibers under study were subjected to chemical treatment 

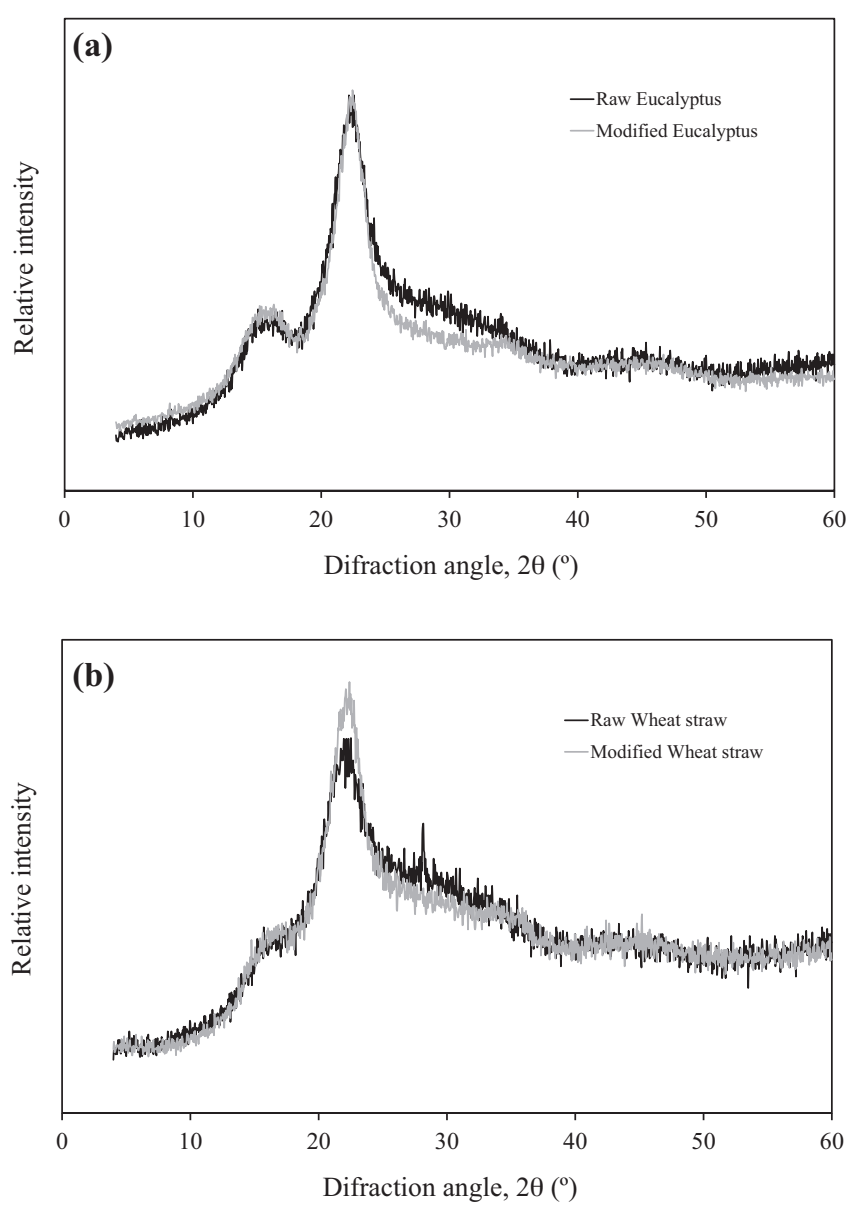

Fig. 2. X-ray diffractogram of eucalyptus (a) and wheat straw (b) raw and treated with $\mathrm{NaOH}$.

with $1 \% \mathrm{NaOH}$ following the TAPPI Test Methods (T 212 om-98). The treatment extracted a significant amount of fibers components. The results are summarized in Table 1 . Based on previous studies, this chemical treatment removes extractives, waxes, oil, etc., from fibers surfaces, and depending on the alkali process, it can also extract lignin, hemicellulose and pectin (Le Troedec et al., 2008; Sun, Xu, Sun, Fowler, \& Baird, 2005). The extraction of these components can be observed in FTIR spectrum, exemplified by the spectra of wheat straw fibers after alkaline treatment (Fig. 1). The peaks in the region at $1740 \mathrm{~cm}^{-1}$, in the raw fibers attributed to either the acetyl and uronic ester groups of the hemicelluloses or the ester linkage of carboxylic group of the ferulic and $p$-coumaric acids of lignin (Alemdar \& Sain, 2008; Cherian et al., 2008), disappeared in the spectra of the chemically modified fibers, which indicates a complete cleavage of these ester bonds. The intensity of the peaks attributed to $C=C$ of aromatic skeletal vibrations in lignin, in the region of $1500-1600 \mathrm{~cm}^{-1}$, has decreased in chemically modified fibers reflecting partial removal of lignin. Also, the disappearance of the peak around $1260 \mathrm{~cm}^{-1}$ after alkalization indicates the preferential removal of hemicelluloses materials rather than lignin (Mwaikambo \& Ansell, 2002).

Table 2

Crystallinity index (\%) of the raw and modified fibers.

\begin{tabular}{lll}
\hline Fibers & Raw & Modified \\
\hline Eucalyptus & 54.48 & 57.64 \\
Spruce & 54.43 & 55.98 \\
Bagasse & 45.23 & 62.87 \\
Wheat straw & 49.95 & 58.29 \\
\hline
\end{tabular}

Although this chemical transformation in the composition of the fibers, the alkalization of lignocellulosic plant fibers changes the surface topography and their crystallographic structure. Abraham and Pothen (2010) investigated the effect of alkali treatment on different natural fibers by XRD and observed an increase in the crystallinity index of the natural fibers upon mercerization. Similar results were observed in present study. An increase in the crystallinity was observed and can be seen by the example given in Fig. 2 for eucalyptus and wheat straw fibers. The X-ray diffractograms show that the intensity of the $I_{002}$ crystallographic peak was increased by alkali treatment of the fibers with more relevance to the agro-fibers. This increase in the crystallinity can be attributed to the removal of extractives and cementing amorphous components like lignin, hemicellulose and pectin. The $\mathrm{CI}$ results (Table 2) confirm this observation, and show a higher crystallinity of agrofibers in the opposition to the observed raw samples. The alkaline treatment has a more strong effect in the bagasse fiber, increasing the $\mathrm{CI}$ by $39 \%$, followed by the wheat straw with an increase of $17 \%$. In the case of wood fibers the $\mathrm{CI}$ increases by less than $6 \%$.

\subsection{Surface characterization}

In order to study the influence of the alkaline treatment on the surface characteristics of the fibers, the raw and the modified fibers were studied by inverse gas chromatography (IGC). In this work, the dispersive component of the surface energy, $\gamma_{S}^{\mathrm{D}}$, was obtained by the application of the method of Schultz, Lavielle, and Martin (1989):

$\Delta G_{\mathrm{ads}}^{\mathrm{D}}=R T \ln V_{\mathrm{N}}=2 N_{\mathrm{A}}\left(\gamma_{\mathrm{S}}^{\mathrm{D}}\right)^{1 / 2} a\left(\gamma_{\mathrm{L}}^{\mathrm{D}}\right)^{1 / 2}+$ const.

where $\Delta G_{\mathrm{ads}}^{\mathrm{D}}$ is the dispersive free energy of adsorption, $V_{\mathrm{N}}$ is the net retention volume, $\gamma_{S}^{\mathrm{D}}$ and $\gamma_{\mathrm{L}}^{\mathrm{D}}$ the dispersive component of the surface tension of the solid material and the probe molecule, respectively, $a$ is the cross sectional area of the probe molecule and $N_{\mathrm{A}}$ the Avogadro constant.

Fig. 3 shows, as example, the plot of $R T \ln V_{N}$ versus $a\left(\gamma_{L}^{\mathrm{D}}\right)^{1 / 2}$ for the $n$-alkanes series in raw and modified fibers at $298 \mathrm{~K}$. In the present study, excellent linear corrections (0.994-0.9996) were obtained for the $n$-alkanes series in all samples undertaken for analysis. $\gamma_{S}^{\mathrm{D}}$ was determined at four different temperatures $(293,296$, 298 , and $300 \mathrm{~K}$ ). The results are listed in Table 3. It was observed that the $\gamma_{\mathrm{S}}^{\mathrm{D}}$ decreases linearly with increase in temperature. The $\gamma_{\mathrm{S}}^{\mathrm{D}}$ decrease with the temperature is frequently observed in lignocellulosic materials (Cordeiro, Gouveia, \& Jacob John, 2011a).

On the surface of lignocellulosic fibers, polar groups (such as hydroxyl and carboxylate) are located that are able to exchange dispersive, but also specific interactions with polar probes. Therefore, the surface interaction with polar probes was also studied for all the samples. The specific free energy of adsorption, $\Delta G_{\mathrm{ads}}^{\mathrm{sp}}$, is calculated by the difference between the surface acid-base parameters using the Gutmann (1978) concept:

$-\frac{\Delta G_{\mathrm{ads}}^{\mathrm{sp}}}{A N *}=K_{\mathrm{a}} \frac{D N}{A N *}+K_{\mathrm{b}}$

where $D N$ and $A N^{*}$ are the donor and acceptor values of the polar probes, respectively. The constants $K_{\mathrm{a}}$ and $K_{\mathrm{b}}$ characterize the ability of the sample to accept or to donate electrons, and were determined from graphic representation of $-\Delta G_{\text {ads }}^{\mathrm{sp}} / A N *$ versus $D N / A N^{*}$ (Fig. 4; Table 4). The correlation coefficients determined by the linear fitting of the data for all samples under study, were in the range 0.96-0.99, showing that the Gutmann's acid-base concept is valid for the studied samples, and that the specific interactions may be considered to be of the electron donor-acceptor type. 
Table 3

Dispersive component of the surface tension $\left(\mathrm{mJ} / \mathrm{m}^{2}\right)$ of the raw and modified fibers surfaces.

\begin{tabular}{|c|c|c|c|c|c|}
\hline & \multicolumn{4}{|c|}{$\gamma_{\mathrm{S}}^{\mathrm{D}}\left(\mathrm{mJ} / \mathrm{m}^{2}\right)$} & \multirow[t]{2}{*}{ Correlation coefficient } \\
\hline & $293 \mathrm{~K}$ & $296 \mathrm{~K}$ & $298 \mathrm{~K}$ & $300 \mathrm{~K}$ & \\
\hline \multicolumn{6}{|l|}{ Eucalyptus } \\
\hline Raw & 44.39 & 43.60 & 43.20 & 42.41 & 0.984 \\
\hline Modified & 44.00 & 43.05 & 42.72 & 42.22 & 0.985 \\
\hline \multicolumn{6}{|l|}{ Spruce } \\
\hline Raw & 43.26 & 42.23 & 41.61 & 41.19 & 0.990 \\
\hline Modified & 45.92 & 44.63 & 44.18 & 43.27 & 0.988 \\
\hline \multicolumn{6}{|l|}{ Bagasse } \\
\hline Raw & 46.39 & 44.90 & 44.24 & 43.15 & 0.994 \\
\hline Modified & 44.16 & 43.18 & 42.82 & 42.12 & 0.989 \\
\hline \multicolumn{6}{|l|}{ Wheat straw } \\
\hline Raw & 47.57 & 45.91 & 45.06 & 44.47 & 0.982 \\
\hline Modified & 52.13 & 50.27 & 48.82 & 48.02 & 0.991 \\
\hline
\end{tabular}
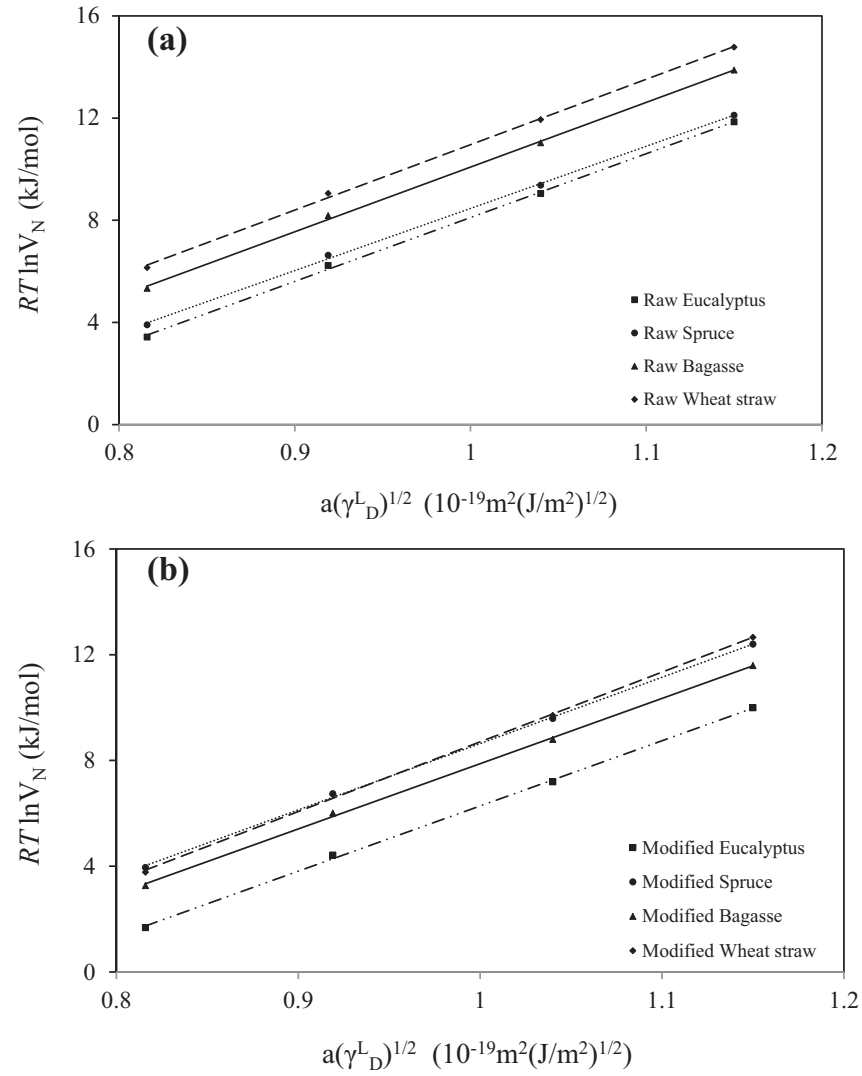

Fig. 3. Plot of $R T \ln V_{\mathrm{N}}$ versus a $\left(\gamma_{\mathrm{L}}^{\mathrm{D}}\right)^{1 / 2}$ for the $n$-alkanes onto raw (a) and modified (b) fibers at different temperatures.

Table 4

Acid/base constants obtained for the raw and modified fibers at $298 \mathrm{~K}$.

\begin{tabular}{lllll}
\hline Fibers & $K_{\mathrm{a}}$ & $K_{\mathrm{b}}$ & $K_{\mathrm{b}} / K_{\mathrm{a}}$ & Correlation coefficient \\
\hline Eucalyptus & & & & \\
$\quad$ Raw & 0.09 & 0.31 & 3.44 & 0.963 \\
$\quad$ Modified & 0.08 & 0.43 & 5.37 & 0.972 \\
Spruce & & & & \\
$\quad$ Raw & 0.08 & 0.33 & 4.13 & 0.956 \\
$\quad$ Modified & 0.08 & 0.45 & 5.63 & 0.972 \\
Bagasse & & & & \\
$\quad$ Raw & 0.10 & 0.13 & 1.30 & 0.992 \\
$\quad$ Modified & 0.09 & 0.28 & 3.11 & 0.986 \\
$\quad$ Wheat straw & & & & \\
$\quad$ Raw & 0.12 & 0.12 & 1.09 & 0.995 \\
$\quad$ Modified & 0.11 & 0.28 & 2.54 & 0.988 \\
\hline
\end{tabular}

The strength of the interaction between the surface of a solid and a gas molecules adsorbed on the surface can be directly measured by the heat of adsorption, $Q$ :

$Q=R \frac{d\left(\ln V_{\mathrm{N}}\right)}{d(1 / T)}$

In this study, $Q$ was determined with a non-polar probe, $n$ octane, and with the four polar probes: tetrahydrofuran, ethyl acetate, acetonitrile and ethanol, at 293, 296, 298, and $300 \mathrm{~K}$ (Fig. 2). Excellent linearity's was obtained $(>0.98)$. Although $Q$ is dependent on the probe molecule and the surface properties, its study allows the understanding of the variations in surface acid-base characteristics of a material during a transformation process. In the present work, the interaction between the different fibers and all polar probes (Fig. 5) indicates the presence of both acidic and basic sites on the fibers surface.

The isotherm experimental, done with the $n$-octane probe, shows symmetrical peaks for all the studied fibers, typical of linear adsorption isotherms described by Henry's Law, and highlights that $n$-octane interacts only with the surface of the fibers (Fig. 6).

Using the BET approach, the monolayer capacity, $n_{\mathrm{m}}$, and the surface area, $S_{\mathrm{BET}}$, were determined, as explained in detail by Condor and Young (1979). The results are presented in Table 5.

The examination of the surface properties of the fibers using IGC at finite concentration conditions, gives also access to information on the surface heterogeneity (Cordeiro, Gouveia, Moraes, et al., 2011). In the present work, the surface heterogeneity was determined by the variation of the $n$-octane concentration. For all the samples the curves (Fig. 7) have only one peak maximum, $A_{\max }$, with energies between 10 and $14 \mathrm{~kJ} / \mathrm{mol}$.

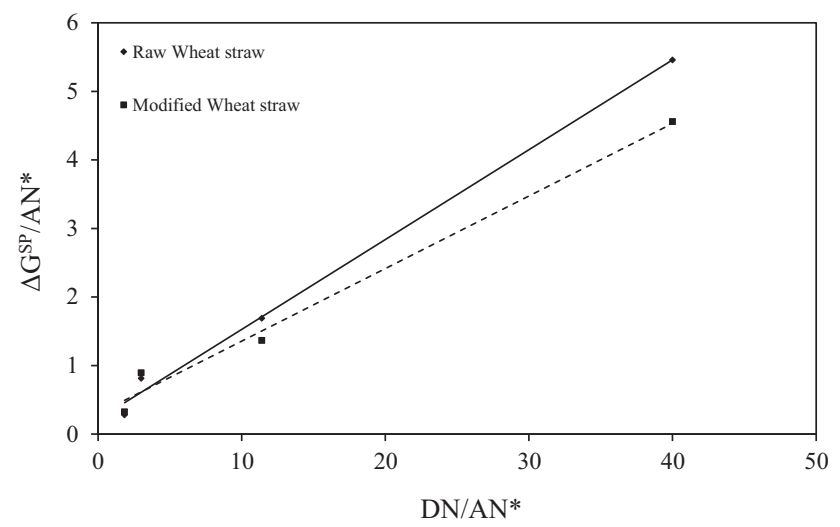

Fig. 4. Plot of $\Delta \mathrm{G}_{\mathrm{ads}}^{\mathrm{sp}} / A N^{*}$ versus $D N / A N^{*}$ for wheat straw before and after $\mathrm{NaOH}$ treatment. 

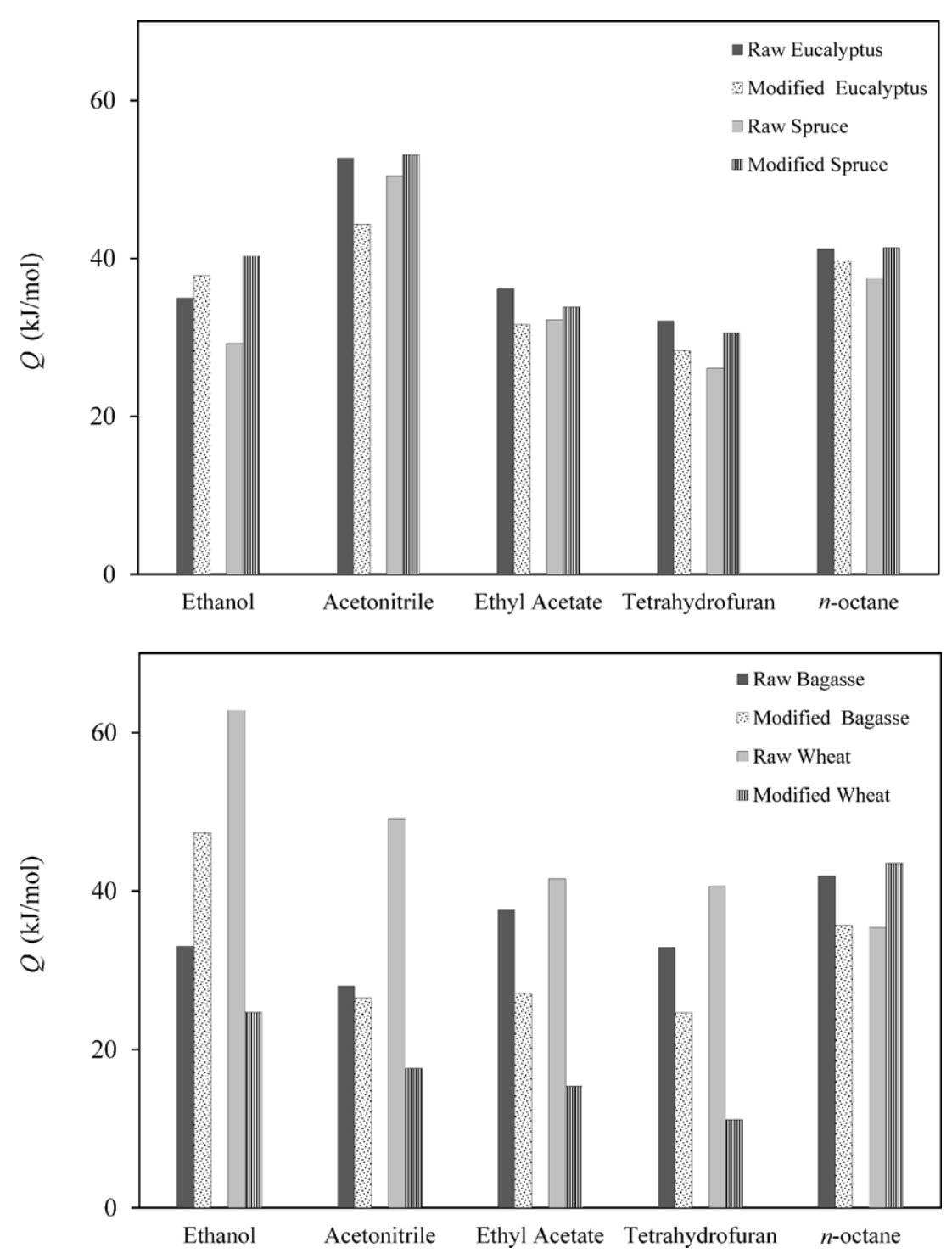

Fig. 5. Heat of adsorption obtained for raw and modified fibers at $298 \mathrm{~K}$.

\subsubsection{Dispersive surface energy}

Among the studied raw fibers, the non-wood samples present the highest value of the $\gamma_{S}^{\mathrm{D}}$ when compared with the wood fibers (Table 3). Wheat straw presented the highest value of the $\gamma_{S}^{\mathrm{D}}$ $\left(47.57 \mathrm{~mJ} / \mathrm{m}^{2}\right.$, at $\left.293 \mathrm{~K}\right)$ while spruce fiber exhibited the lowest value of $\gamma_{\mathrm{S}}^{\mathrm{D}}\left(43.26 \mathrm{~mJ} / \mathrm{m}^{2}\right.$, at $\left.293 \mathrm{~K}\right)$. These values are close to those reported in the literature for similar materials. Mills et al. (2008) reported a dispersive surface energy for wheat straw of $40.9 \mathrm{~mJ} / \mathrm{m}^{2}$ at $293 \mathrm{~K}$. Walinder and Gardner (2000) reported a dispersive energy for Norway spruce wood of $42 \mathrm{~mJ} / \mathrm{m}^{2}$ at $293 \mathrm{~K}$ and Aquino et al. (2002) reported a dispersive energy, for eucalyptus of $41.3 \mathrm{~mJ} / \mathrm{m}^{2}$ at 313 K. Cordeiro, Gouveia, and Jacob John (2011), Cordeiro, Gouveia,
Moraes, et al. (2011), found $\gamma_{\mathrm{S}}^{\mathrm{D}}$ ranged from 37.17 to $51.37 \mathrm{~mJ} / \mathrm{m}^{2}$, at $298 \mathrm{~K}$, for various lignocellulosic fibers, namely piassava, jute, sorghum, ramie, pita Mexicana, curaua, sisal, flax, hemp, kenaf, agave, agave hybrid and pineapple.

The variation in surface energy can be explained by the chemical composition of lignocellulosic fibers which depends on various factors such as species, variety, farming type of soil, weather conditions, plant part from which the fibers are extracted, age of the plant, etc. (Rowell et al., 2000; Satyanarayana \& Wypych, 2007).

Previous works (Mills et al., 2008; Cordeiro, Gouveia, \& Jacob John, 2011; Cordeiro, Gouveia, Moraes, et al., 2011) associate the $\gamma_{\mathrm{S}}^{\mathrm{D}}$ increase with lignin decrease and cellulose increase content of

Table 5

Adsorption potential distribution maximum, specific surface area and monolayer capacity for the raw and modified fibers at $298 \mathrm{~K}$.

\begin{tabular}{|c|c|c|c|c|c|c|}
\hline \multirow[t]{2}{*}{ Fibers } & \multicolumn{3}{|l|}{ Raw } & \multicolumn{3}{|l|}{ Modified } \\
\hline & $A_{\max }(\mathrm{kJ} / \mathrm{mol})$ & $S_{\mathrm{BET}}\left(\mathrm{m}^{2} / \mathrm{g}\right)$ & $n_{\mathrm{m}}(\mu \mathrm{mol} / \mathrm{g})$ & $A_{\max }(\mathrm{kJ} / \mathrm{mol})$ & $S_{\mathrm{BET}}\left(\mathrm{m}^{2} / \mathrm{g}\right)$ & $n_{\mathrm{m}}(\mu \mathrm{mol} / \mathrm{g})$ \\
\hline Eucalyptus & 11.89 & 0.81 & 2.13 & 10.08 & 0.48 & 1.26 \\
\hline Spruce & 11.20 & 1.19 & 3.15 & 10.97 & 0.82 & 2.15 \\
\hline Bagasse & 14.15 & 1.07 & 2.82 & 11.34 & 0.96 & 2.52 \\
\hline Wheat straw & 14.13 & 0.95 & 2.50 & 14.20 & 0.60 & 1.58 \\
\hline
\end{tabular}




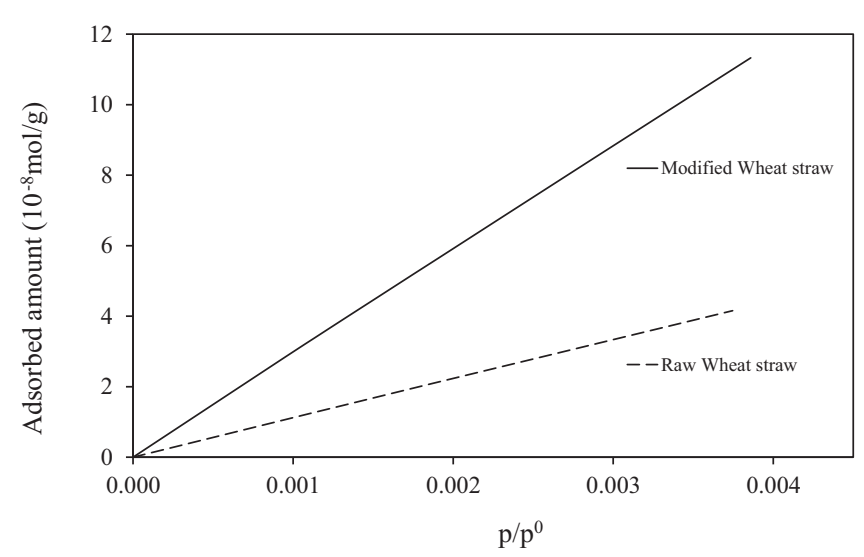

Fig. 6. n-octane isotherms obtained for fibers before and after $\mathrm{NaOH}$ treatment.

the analyzed material. However, the retention of the probes, and consequent IGC data, could be influenced by other parameters such as crystallinity and the arrangement and orientation of chemical groups in the surface (Belgacem, Blayo, \& Gandini, 1996; Papirer, Brendle, Balard, \& Vergelati, 2000).

As concluded by the chemical characterization, the alkaline treatments modify the composition of the samples, which results in $\gamma_{S}^{\mathrm{D}}$ changes (Table 3 ). The modified fibers, wheat straw and spruce fibers, show higher $\gamma_{S}^{\mathrm{D}}$, than the respective raw fibers. On the contrary, the modified eucalyptus and bagasse show lower $\gamma_{S}^{\mathrm{D}}$, than the respective raw fibers. The change in the dispersive component of the fiber surface can be also evaluated by $Q$ parameter
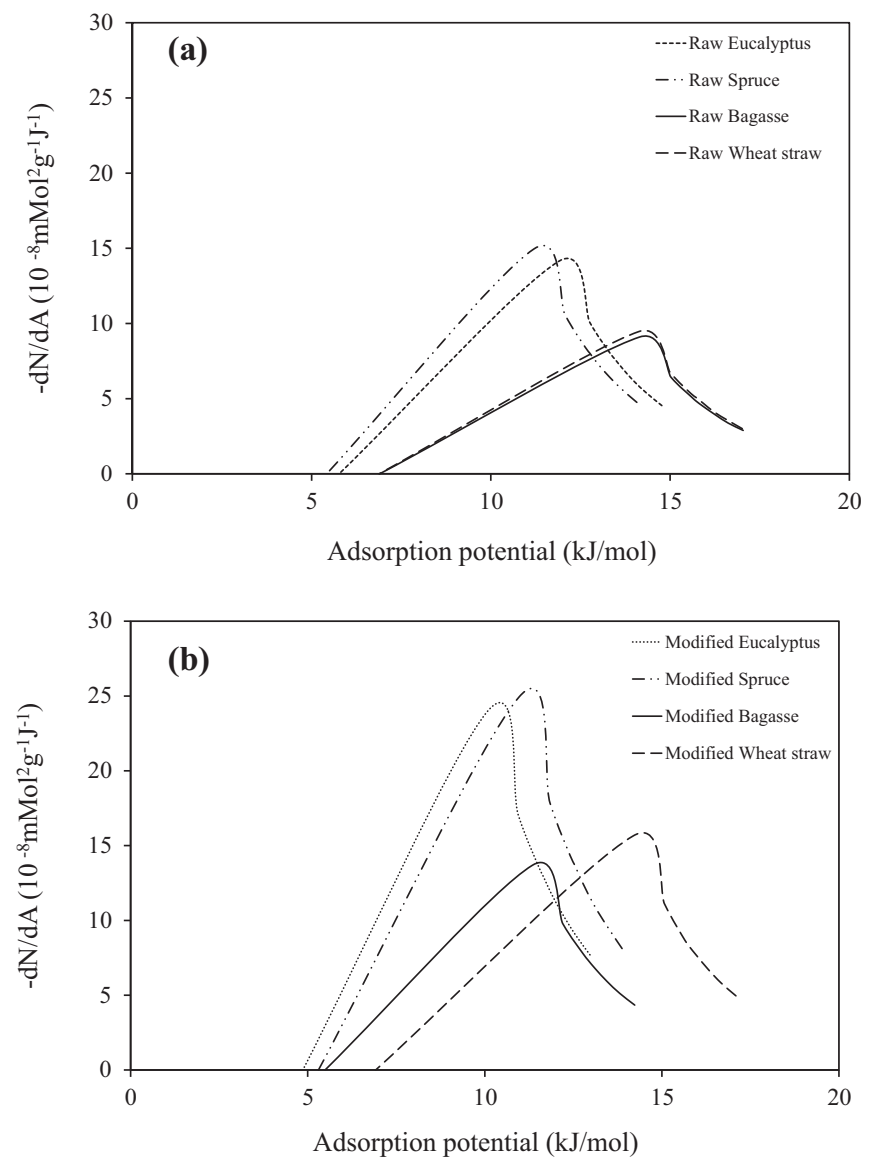

Fig. 7. Heterogeneity profiles obtained with $n$-octane at $298 \mathrm{~K}$ for (a) before $\mathrm{NaOH}$ treatment and (b) after $\mathrm{NaOH}$ treatment. using a non-polar probe. The $Q$ values obtained for the n-octane in the raw fibers were 35.39 and $37.47 \mathrm{~kJ} / \mathrm{mol}$, and they increased to 43.53 and $41.36 \mathrm{~kJ} / \mathrm{mol}$ after treatment, for wheat straw and spruce fibers, respectively (Fig. 5). In the case of the $\gamma_{S}^{\mathrm{D}}$ decrease, a similar tendency is observed in $Q$ values.

Since $n$-alkane probes are able to interact only through dispersion interactions, the increased $\gamma_{\mathrm{S}}^{\mathrm{D}}$ for modified fibers was an indication that the fibers became with more hydrophobic actives sites (Matuana, Balatinecz, Park, \& Woodhams, 1999). This increase can be due to the increase in number and/or in the energy of the active sites. As example, the energetic profile show that the modified wheat straw fibers (Fig. 7b) present active sites more energetic $\left(A_{\max }\right.$ at $\left.15.20 \mathrm{~kJ} / \mathrm{mol}\right)$ than in raw material $\left(A_{\max }\right.$ at $\left.14.13 \mathrm{~kJ} / \mathrm{mol}\right)$. On the other hand, the energetic profile of the modified bagasse (Fig. 7b) shows the presence in their surface of less energetic active sites $\left(A_{\max }\right.$ at $\left.11.34 \mathrm{~kJ} / \mathrm{mol}\right)$ than in the raw material $\left(A_{\max }\right.$ at $14.15 \mathrm{~kJ} / \mathrm{mol}$ ). As referred above, a decrease in the $\gamma_{\mathrm{S}}^{\mathrm{D}}$ can be also due to the reduction in the number of the non-polar sites on the surface. In the present case, the mercerization can remove waxy material (small non-polar molecules) and thus should leave the surface richer in cellulose, with polar hydroxyl groups in a more exposed conformation lowering the $\gamma_{S}^{\mathrm{D}}$ (Ass, Belgacem, \& Follini, 2006). The reduction in the $\gamma_{S}^{\mathrm{D}}$ values can be due also to the protective coating formed by the moieties created by the partial depolymerisation of lignin. The FTIR and the XRD analyses have confirmed the increased cellulose content of the fibers after $\mathrm{NaOH}$ treatment (Table 2; Fig. 2), due to the dissolution of the extractives, hemicelluloses and lignin components in the fiber. Li, Tabil, and Satyanarayan (2007) found that the alkaline treatment used in chemical treatment of vegetable fibers causes disruption of hydrogen bonds and removal of amorphous portions (hemicellulose, lignin and pectins) and impurities, raising the content of exposed cellulose on the fiber.

\subsubsection{Acid-base surface characteristics}

FTIR spectra indicate that alkaline treatment removes some components but how this affects the acid-base surface proprieties? Can these alterations have impact on their adhesive bond quality?

As referred above, using different polar probes (acetonitrile, ethanol, ethyl acetate and tetrahydrofuran) the $Q$ values were obtained. Greater changes in $Q$ values were observed for all the polar probes (Fig. 5), which is indicative of modifications in acid and base active sites during the alkaline treatment. The highest increase in $Q$ was observed for the ethanol, probe with lower $D N / A N^{*}$, when compared to the probe with higher $D N / A N^{*}$, in the case of bagasse fiber, suggesting that the alkaline treatment increased predominantly the basic groups in the fiber surfaces. The decrease in $Q$ values for the THF (the more acid probe) for all the fibers, supports the indication given by the FTIR spectra about the removal of acidic groups by alkaline treatment. In the case of spruce fibers, the $Q$ decreases for all the polar probes. This indicates that the alkaline treatment changes significantly the surface with a decrease in the polar active sites used in the specific interactions.

Relative to specific free energy of adsorption, $\Delta G_{\mathrm{s}}^{\mathrm{sp}}$, calculated according to Eq. (2), the data at $298 \mathrm{~K}$ are shown in Fig. 8 . All the raw and modified fibers exhibited maximum interaction with acetonitrile, which is an amphoteric compound that can interact with both the acidic and basic groups, which is indicative of both groups in the fibers surface. Fig. 8 shows increase in ethanol $\Delta G_{\text {ads }}^{\text {sp }}(16-143 \%)$ with the alkaline treatment for all the fibers, clearly indicating that the alkaline treatment creates new basic active sites for specific interactions. On the other hand, the $\Delta G_{\text {ads }}^{\text {sp }}$ decrease in the THF probe can be due to acid active sites removal. 

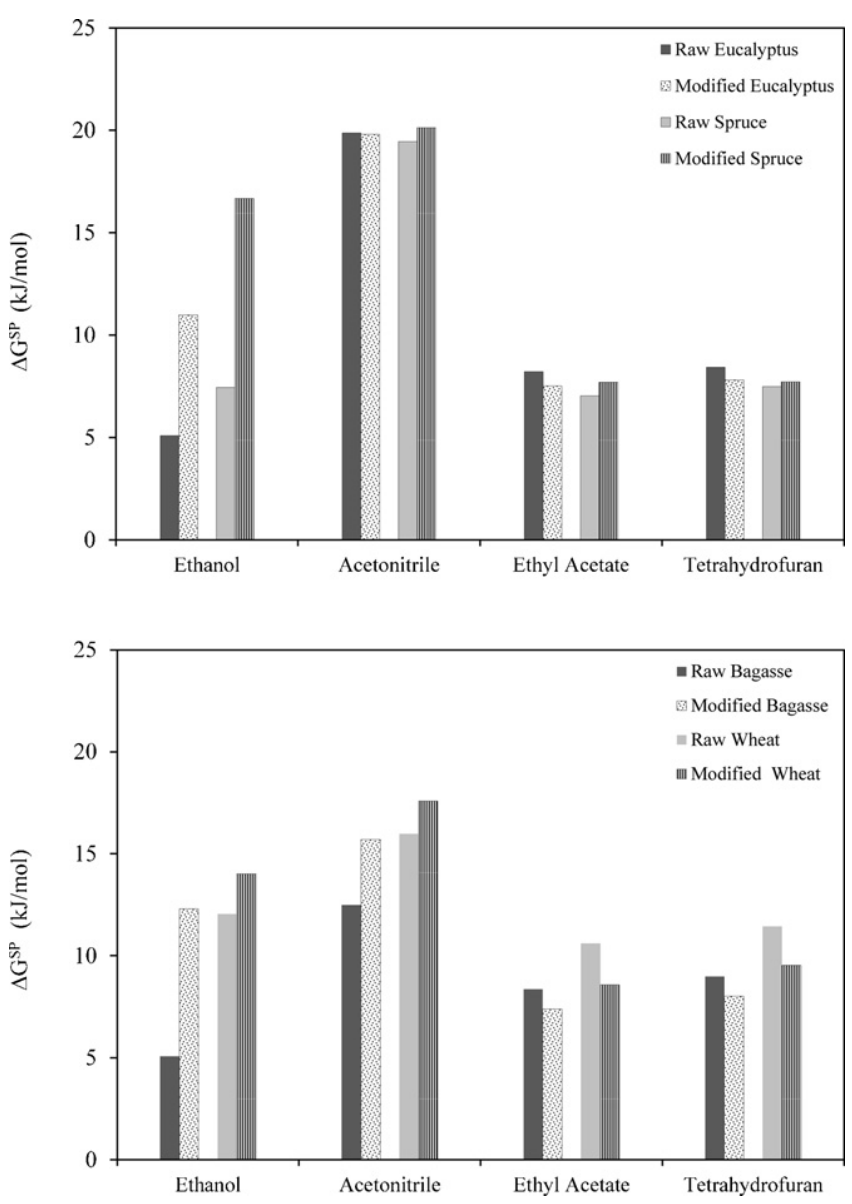

Fig. 8. Specific free energy of adsorption $\left(\Delta \mathrm{G}_{\mathrm{ads}}^{\mathrm{sp}}\right)$ obtained for raw and modified fibers at $298 \mathrm{~K}$.

In terms of acid-base constants (calculated by $\Delta G_{\text {ads }}^{\text {sp }}$ using Eq. (3)) the $K_{\mathrm{a}}$ is lower than the $K_{\mathrm{b}}$ for all the samples (Table 4 ), which means that all the samples show stronger basicity. This property can be attributed to the strong basicity and weak acidity of cellulose and hemicelluloses. Bagasse fibers exhibited the lowest ratio of $K_{\mathrm{b}} / K_{\mathrm{a}}(1.09)$ and the spruce fiber exhibited the highest ratio of $K_{\mathrm{b}} / K_{\mathrm{a}}$ (4.13). The same Lewis basic predominant characters were also found by Cordeiro, Gouveia, Moraes, et al., (2011) in the piassava $\left(0.09\right.$ to $K_{\mathrm{a}}$ and 0.15 to $\left.K_{\mathrm{b}}\right)$, jute $\left(0.10\right.$ to $K_{\mathrm{a}}$ and 0.17 to $\left.K_{\mathrm{b}}\right)$, sorghum ( 0.10 to $K_{\mathrm{a}}$ and 0.15 to $K_{\mathrm{b}}$ ), ramie ( 0.10 to $K_{\mathrm{a}}$ and 0.18 to $\left.K_{\mathrm{b}}\right)$, pita Mexicana $\left(0.09\right.$ to $K_{\mathrm{a}}$ and 0.36 to $\left.K_{\mathrm{b}}\right)$, curaua $\left(0.11\right.$ to $K_{\mathrm{a}}$ and 0.14 to $K_{\mathrm{b}}$ ) and sisal ( 0.09 to $K_{\mathrm{a}}$ and 0.12 to $K_{\mathrm{b}}$ ). Mills et al. (2008) also reported basic character onto the surface of bast fibers, namely for hemp ( 0.16 to $K_{\mathrm{a}}$ and 0.49 to $\left.K_{\mathrm{b}}\right)$, flax ( 0.17 to $K_{\mathrm{a}}$ and 0.49 to $K_{\mathrm{b}}$ ) and kenaf $\left(0.07\right.$ to $K_{\mathrm{a}}$ and 0.32 to $\left.K_{\mathrm{b}}\right)$.

For the modified fibers, the wheat straw exhibited the lowest ratio of $K_{\mathrm{b}} / K_{\mathrm{a}}(2.54)$ and the spruce exhibited the highest ratio of $K_{\mathrm{a}} / K_{\mathrm{b}}$ (5.37). This increase in $K_{\mathrm{b}} / K_{\mathrm{a}}$ ratio was higher for the agro-fibers (133-139\%) compared to the wood-fibers (36-56\%) due principally to the $K_{\mathrm{b}}$ increase.

After alkaline treatment, basic character was found to increase for all fibers. To conclude: the alkaline treatment increases the basic surface character for all the modified samples with more relevance to the agro-fibers.

\subsubsection{Isotherm measurements}

The BET model was used to determine the values of surface area and monolayer capacity (Table 5). The surface area of the raw fibers were found to range between 0.81 and $1.19 \mathrm{~m}^{2} / \mathrm{g}$, corresponding to eucalyptus and spruce fibers, respectively.

A parameter that can be undoubtedly related to surface area is monolayer capacity. The $n$-octane monolayer capacity of the raw fibers was found to vary between $2.13 \mu \mathrm{mol} / \mathrm{g}$ for eucalyptus and $3.15 \mu \mathrm{mol} / \mathrm{g}$ for the spruce fiber. Cordeiro, Gouveia, Moraes, et al. (2011) found for agro-materials $S_{\mathrm{BET}}$ values between 0.382 and $2.793 \mathrm{~m}^{2} / \mathrm{g}$ and $n_{\mathrm{m}}$ values between 0.3 and $7.4 \mu \mathrm{mol} / \mathrm{g}$.

After alkaline treatment, the modified fibers show values for the surface area ranging between 0.48 and $0.96 \mathrm{~m}^{2} / \mathrm{g}$, and to monolayer capacity between $1.26 \mu \mathrm{mol} / \mathrm{g}$ and $2.52 \mu \mathrm{mol} / \mathrm{g}$, corresponding to eucalyptus and bagasse, respectively. This can be indicative of fibers aggregation during the alkaline treatment or/and indicative of less rough or/and perforated samples.

\section{Conclusions}

This study investigated the effects of alkaline treatment on surface properties of Iranian cultivated natural fibers that may have impact on their adhesive bond quality. The following conclusions can be drawn from this study:

1. Alkaline treatment removes some chemical components on the surface of raw fibers, namely uranic acid (hemicellulose), nonpolar molecules (extractives) and aromatic moieties from the partial lignin depolymerisation. The treatment has a higher impact on chemical components of non-wood fibers;

2. Alkaline treatment enhances the crystallinity of non-wood fibers, while in the softwood fibers produces only a slight increase;

3. Alkaline treatment can remarkably improve the specific interaction of the fibers, namely in the interaction with acids agents. This improvement was more significant in the agro-fibers;

4. Alkaline treatment achieves the best overall improvement in the properties evaluated for the agro-fibers when compared to the wood fibers;

5. In general, alkaline treatment can improve wettability of the fibers and reduce the need for coupling agent in wood plastic composite process.

\section{Acknowledgements}

Portuguese authors would like to thank the "Programa Nacional de Re-equipamento Científico", POCI 2010, by sponsored IGC work (FEDER and Foundation for the Science and Technology). The Iranian authors gratefully acknowledge the financial support (grant \# 90001219) from the Iran National Science Foundation (INSF).

\section{References}

Abraham, E., \& Pothen, L. A. (2010). Cellulose nanocomposites for biomedical application. In Proceedings of international conference on nanomaterials: Synthesis characterization and applications (ICN 2010) Kottayam, Kerala, India, (pp. 45-50)

Alemdar, A., \& Sain, M. (2008). Isolation and characterization of nanofibers from agricultural residues-Wheat straw and soy hulls. Bioresource Technology, 99 1664-1671.

Aquino, A. I., Ferreira, P. J., Carvalho, M. G., Amaral, J. L., \& Figueiredo, M. M. (2002). Influence of cooking and bleaching conditions on the surface and paper properties of Eucalyptus globulus kraft pulps. Congresso IberoAmericano de Investigácion en Celulosa y Papel. (CIADICYP).

Ass, B. A. P., Belgacem, M. N., \& Follini, E. (2006). Mercerized linters cellulose: Characterization and acetylation in N,N-dimethylacetamide/lithium chloride. Carbohydrate Polymers, 63, 19-29.

Belgacem, M. N., \& Gandini, A. (1999). IGC as a tool to characterize dispersive and acid-base properties the surface of fibers and powders. In E. Pfefferkorn (Ed.), Interfacial phenomena in chromatography (pp.41-124). New York: Marcel Dekker Inc.

Belgacem, M. N., Blayo, A., \& Gandini, A. (1996). Surface characterization of polysaccharides, lignins, printing ink pigments, and ink fillers by inverse gas chromatography. Journal of Colloid and Interface Science, 182, 431-436. 
Cherian, B. M., Pothan, L. A., Nguyen-Chung, T., Menning, G., Kottaisamy, M., \& Thomas, S. (2008). A novel method for the synthesis of cellulose nanofibril whiskers from banana fibers and characterization. Journal of Agricultural and Food Chemistry, 56, 5617-5627.

Condor, J., \& Young, C. (1979). Physicochemical measurement by gas chromatography. Chichester, UK: John Wiley and Sons.

Cordeiro, N., Gouveia, C., \& Jacob John, M. (2011). Investigation of surface properties of physico-chemically modified natural fibres using inverse gas chromatography. Industrial Crops and Products, 33, 108-115.

Cordeiro, N., Gouveia, C., Moraes, A. G. O., \& Amico, S. C. (2011). Natural fibers characterization by inverse gas chromatography. Carbohydrate Polymers, 84, 110-117.

Eichhorn, S. J., Bailie, C. A., Zafeiropoulos, N., Mwaikambo, L. Y., et al. (2001). Current international research into cellulosic fibres and composites. Journal of Materials Science, 36, 2107-2131.

El-Zawawy, W. K. (2006). Blended graft copolymer of carboxymethyl cellulose and poly (vinyl alcohol) with banana fiber. Journal of Applied Polymer Science, 100, 1842-1848.

Fengel, D., \& Wegener, G. (1983). Wood: Chemistry, ultrastructure reactions. Berlin: de Gruyter., pp. 482-488.

Gañán, P., Cruz, J., Garbizu, S., Arbelaiz, A., \& Mondragon, I. (2004). Stem and bunch banana fibers from cultivation wastes: Effect of treatments on physico-chemical behavior. Journal of Applied Polymer Science, 94, 1489-1495.

Gutmann, V. (1978). The donor-acceptor approach to molecular interactions. New York: Plenum Publ. Corp.

Hamzeh, Y., Ashori, A., \& Mirzaei, B. (2011). Effects of waste paper sludge on the physico-mechanical properties of high density polyethylene/wood flour composites. Polymers and the Environment, 19, 120-124.

Kim, J.-W., Harper, D. P., \& Taylor, A. M. (2009). Effect of extractives on water sorption and durability of wood-plastic composites. Wood and Fiber Science, 41, 279-290.

Le Troedec, M., Sedan, D., Peyratout, C., Bonnet, J. P., Smith, A., Guinebretiere, R., et al. (2008). Influence of various chemical treatments on the composition and structure of hemp fibres. Composites Part A, 39, 514-522.

Li, X., Tabil, L. G., \& Satyanarayan, P. (2007). Chemical treatments of natural fibre for use in natural fibre-reinforced composites: A review. Journal of Polymers and the Environment, 15, 25-33.

Matuana, L. M., Balatinecz, J. J., Park, C., \& Woodhams, R. T. (1999). Surface characteristics of chemically modified newsprint fibres determined by inverse gas chromatography. Wood and Fiber Science, 31, 116-127.

Mills, R. H., Gardner, D. J., \& Wimmer, R. (2008). Inverse gas chromatography for determining the dispersive surface free energy and acid-base interactions of sheet molding compound-Part II 14 ligno-cellulosic fiber types for possible composite reinforcement. Journal of Applied Polymer Science, 110, 3880-3888.

Mwaikambo, L. Y., \& Ansell, M. P. (2002). Chemical modification of hemp, sisal, jute, and kapok fibers by alkalization. Journal of Applied Polymer Science, 84, 2222-2234.

Nourbakhsh, A., Ashori, A., Ziaei Tabari, H., \& Rezaei, F. (2010). Mechanical and thermo-chemical properties of wood-flour polypropylene blends. Polymer Bulletin, 65, 691-700.
Papirer, E., Brendle, E., Balard, H., \& Vergelati, C. (2000). Inverse gas chromatography investigation of the surface properties of cellulose. Journal of Adhesion Science and Technology, 14, 321-337.

Reddy, N., \& Yang, Y.(2005). Structure and properties of high quality natural cellulose fibers from cornstalks. Polymer, 46, 5494-5500.

Rowell, R. M., Han, J. S., \& Rowell, J. S. (2000). Characterization and factors affecting fiber properties. In E. Frollini, A. L. Leão, \& L. H. C. Mattoso (Eds.), Natural polymers and agrofibers composites (pp. 115-134). São Carlos, Brasil: USP/UNESP and Embrapa.

Satyanarayana, K. G., \& Wypych, F. (2007). Characterization of natural fibers. In S. Fakirov, \& D. Bhattacharya (Eds.), Engineering biopolymers homopolymers, blends and composites (pp. 3-48). Munich: Hanser Publishers.

Schultz, J., Lavielle, L., \& Martin, C. (1989). D. R. Lloyd, T. C. Ward, \& H. P. Schreiber (Eds.), Inverse gas chromatography: Characterization of polymers and other materials (pp. 185-202). ACS Symposium Series.

Segal, L., Creely, J. J., Martin, A. E., \& Conrad, C. M. (1959). An empirical method for estimating the degree of crystallinity of native cellulose using the X-ray diffractometer. Textile Research Journal, 29, 764-786.

Shebani, A. N., van Reenena, A. J., \& Meincken, M. (2009). The effect of wood extractives on the thermal stability of different wood-LLDPE composites. Thermochimstry Acta, 481, 52-56.

Sheshmani, S., Ashori, A., \& Farhani, F. (2012). Effects of extractives on the performance properties of wood flour-polypropylene composites. Applied Polymer Science, 123, 1563-1567.

Sjöström, E. (1993). Wood chemistry: Fundamentals and applications ( $2^{\text {nd }}$ ed.). USA Academic: San Diego.

Sun, X. F., Xu, F., Sun, R. C., Fowler, P., \& Baird, M. S. (2005). Characteristics of degraded cellulose obtained from steam-exploded wheat straw. Carbohydrate Research, 340, 97-106.

(2002). TAPPI test methods. Atlanta, GA: Tappi Press.

Tze, W. T. Y., Wålinder, M. E. P., \& Gardner, D. J. (2006). Inverse gas chromatography for studying interactions of materials used for cellulose fiber/polymer composites. Journal of Adhesion Science and Technology, 20, 743-759.

Van de Weyenberg, I., Chi Truong, T., Vangrimde, B., \& Verpoest, I. (2006). Improving the properties of UD flax fibre reinforced composites by applying an alkaline fibre treatment. Composites Part A, 37, 1368-1376.

Walinder, M. E. P., \& Gardner, D. J. (2000). Surface energy of extracted and nonextracted Norway spruce wood particles studied by inverse gas chromatography (IGC). Wood and Fiber Science, 32, 478-488.

Wise, E. L., \& Karl, H. L. (1962). Cellulose and hemicellulose. In C. E. Libby (Ed.), Pulp and paper science and technology, pulp. New York, NY, USA: McGraw Book Co.

Ziaei Tabari, H., Nourbakhsh, A., \& Ashori, A. (2011). Effects of nanoclay and coupling agent on the mechanical, morphological, and thermal properties of wood flour/polypropylene composites. Polymer Engineering and Science, 51, 272-277. 